
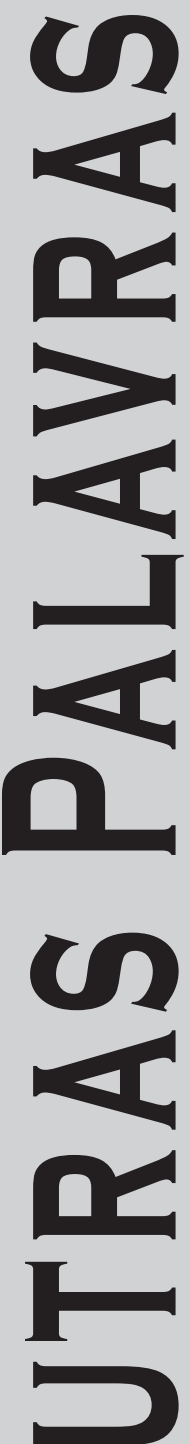

Revista Música Hodie, Goiânia - V.14, 238p., n.1, 2014 


\title{
Conrado Silva (1940-2014) - Um Legado para a Música Eletroacústica Brasileira
}

Prof. Dr. Anselmo Guerra (Universidade Federal de Goiás, Goiânia, GO) guerra.anselmo@gmail.com

\begin{abstract}
Resumo: Este é um artigo em homenagem a Conrado Silva (1940-2014), uruguaio que se radicou no Brasil e dedicou toda uma vida ao ensino, pesquisa e produção artística nas áreas de acústica arquitetônica e música eletroacústica. Atuou com sucesso na divulgação e integração da música contemporânea na América Latina e influenciou gerações de compositores brasileiros que devem a ele o reconhecimento pelo seu trabalho.

Palavras-chave: Conrado Silva; História da música eletroacústica no Brasil; Cursos larinoamericanos de música contemporânea para latino-americanos.
\end{abstract}

Conrado Silva (1940-2014) - A legacy for the Brazilian Electroacoustic Music

Abstract: This is an article in honor of Conrado Silva (1940-2014), an Uruguayan who settled in Brazil and has devoted a lifetime to teaching, research and artistic production in the fields of architectural acoustics and electroacoustic music. He worked successfully in the dissemination and integration of contemporary music in Latin America and influenced generations of Brazilian composers who owe him recognition for his work.

Keywords: Conrado Silva; Brazilian electroacoustic music history; Latinamerican contemporary music courses.

\section{Introdução}

Conrado Silva de Marco nasceu em Montevidéu, Uruguai, em 1940. Estudou com Héctor Tosar e frequentou vários cursos de férias e workshops, sob a direção de Boulez, Stockhausen, Kagel, Ligeti, Riedl, Pousseur e Jonh Cage. Especializou-se em acústica arquitetônica e em música eletroacústica. Fixou residência no Brasil a partir de 1969, contratado como professor do Departamento de Música da UnB. Foi o criador de importantes estúdios universitários no Brasil: na UnB em 1969; no Intituto de Artes da Unesp em 1977; e na Faculdade Santa Marcelina em1985. A partir de 1986 criou seu estúdio particular denominado Sintesis. Criou juntamente com Coriúm Aharoniãn os Cursos Latino-americanos de Música Contemporânea, que ocorreram entre 1971 e 1989, em diversos países da América Latina. Coordenou o Núcleo Música Nova em São Paulo. Influenciou gerações de compositores e pesquisadores brasileiros com seu conhecimento técnico, sabedoria e gererosidade ímpar.

\section{Origens da música eletroacústica na América Latina e no Brasil}

Ao pensarmos na música eletroacústica da América Latina e sua consolidação no Brasil, história e biografia de Conrado Silva se entrelaçam profundamente. De acordo com registros do próprio Conrado (SILVA 1985) o provável início da música eletroacústica na América Latina foi em 1958, com os compositores e engenheiros Juan Amenábar e José Vicente Assuar, na Universidade Católica de Santiago do Chile. Assuar passou pela Universidade Técnica de Karlsruhe, na Alemanha (1960), por Caracas (1966), voltando posteriormente à Universidade do Chile (1972). Na Argentina, os primeiros registros surgem em 1969, na Faculdade de Arquitetura da Universidade Nacional de Buenos Aires, com o compositor Kröpfl. Com a criação em 1962 do Centro Latino Americano de Altos Estudos 
Musicais do Instituto Torquato Di Tella, sob a direção de Alberto Ginastera, foi confiado a Kröpfl um estúdio de música eletroacústica que tornou-se referência na América Latina, atuando como centro de pesquisa, criação, inclusive fornecendo bolsas de estudos a jovens compositores latino-americanos. Dessa geração, Conrado Silva e Coriúm Aharoniãn, também uruguaio, desenvolveram posteriormente um trabalho em forma de cooperativa - Núcleo Música Nova (1965) e ELAC (1974). No Brasil, a música eletroacústica iniciou no Instituto Villa Lobos, com Reginaldo Carvalho, e mais tarde com Jorge Antunes, em meados da década de 1960. Em 1970, Conrado Silva se radicou no Brasil para criar um estúdio na UnB, e em 1978 no Instituto de Artes da Unesp, no qual tive o privilégio de ser seu aluno, e posteriormente membro do Núcleo Música Nova de São Paulo na década de 1980.

\title{
2. Os cursos Latino-americanos de música contemporânea e a integração latino- americana
}

Criados por Conrado Silva e Coriúm Aharoniãn, os Cursos Latino-americanos de Música Contemporânea ocorreram entre 1971 e 1989 inicialmente no Uruguai e depois, por conta do regime ditatorial, em outros países, inclusive no Brasil (AHARONIÁN 1992 e 2007). Autores como Teresinha Rodrigues Prada Soares (2006 e 2006a) e João Marcos Coelho (2008a) identificam nos Cursos Latino-americanos uma postura politizada, inspirada no movimento estudantil de 1968, pregando ideologia de resistência às ditaduras então vigentes na América Latina. Festival Música Nova (Criado por Gilberto Mendes em 1962, onde a produção eletroacústica encontrou espaço para difusão e interação) e os Cursos Latino-americanos contribuíram na formação de uma identidade latino-americana e serviram de modelo para várias iniciativas posteriores na formação de grupos e estúdios de música eletroacústica.

Os Cursos Latino-americanos tiveram origem no Uruguai e se espalharam por vários países da América do Sul: Argentina, República Dominicana, Venezuela e Brasil e eram divididos em oficinas, palestras, mesas redondas, audições de gravações e concertos. De acordo com Terezinha Prada -

\begin{abstract}
"Os cursos nasceram do Núcleo de Música Nueva de Montevideo, fundado em 1966 por Coriún Aharonián e Conrado Silva, ambos alunos de Héctor Tosar na ocasião. Os compositores do Núcleo resolveram criar em 1971 o I Curso Latinoamericano de Música Contemporánea que se deu em Cerro del Toro, Uruguai, e logo nesse primeiro evento compareceu o compositor italiano Luigi Nono, famoso por sua obra de vanguarda tanto quanto por seu comprometimento político de esquerda, apoiando e confirmando o ideal dos compositores uruguaios em buscar uma via própria na linguagem composicional, que não ficasse mais sob a tutela histórica da Europa". (SOARES 2006, p. 3)
\end{abstract}

Assim, foram realizadas quinze edições dos cursos, conforme documentado por Coriún AHARONIÁN (2007): Cerro del Toro, Uruguai (1971); Cerro del Toro, Uruguai (1972); Cerro del Toro, Uruguai (1974); Cerro del Toro, Uruguai (1975); Buenos Aires, Argentina (1976); Buenos Aires, Argentina (1977); São João del-Rei, Brasil (1978); São João del-Rei, Brasil (1979); Itapira, Brasil (1989); Santiago de los Caballeros, República Dominicana (1981); Uberlândia, Brasil (1982); Tatuí, Brasil (1984); San Cristóbal, Venezuela (1985); Cerro del Toro, Uruguai (1986); Mendes, Brasil (1989).

Segundo Terezinha Prada, há uma relação íntima entre Cursos Latino-americanos de Música Contemporânea e o Festival Música Nova: 


\begin{abstract}
"Foi ao entrar em contato com os uruguaios e ao passar a frequentar os Cursos que Gilberto Mendes teve interesse em convidar e trazer vários músicos do Curso Latinoamericano de Música Contemporánea para o Festival Música Nova - há pelo menos 40 nomes em comum que transitaram pelos dois eventos. Assim, uma ligação forte entre as duas mostras se estabeleceu ao longo da década de 70 e início dos anos 80". (SOARES 2006, p. 3)
\end{abstract}

Então, a identidade musical contemporânea latino-americana foi construída a partir da orientação predominante esquerdista. Paradoxalmente, nos países de origem hispânica se adotava a estética nacionalista e os compositores brasileiros com quem compartilhavam ideologia política eram de orientação estética universalista, uma vez que os compositores brasileiros nacionalistas adotavam claramente uma postura alinhada ao posicionamento político de direita e, consequentemente, simpáticos à ditadura militar vigente no país.

\title{
3. O retorno à Universidade de Brasília e seus últimos trabalhos
}

Dado o contexto político vigente no Brasil na época ditatorial, Conrado Silva viu-se afastado da UnB, radicando-se em São Paulo. Foi um período em que vinculou-se ao Instituto de Artes do Planalto da UNESP, onde criou o laboratório de eletroacúsica em 1977 e mais tarde na Faculdade Santa Marcelina (1985). Nesse intervalo de tempo publicou o livro "Elementos de Acústica Arquitetônica” (SILVA 1982). Desenvolveu vários projetos de acústica arquitetônica através de sua empresa denominada "Consultor”. Nessa época também liderou o Núcleo Música Nova que, entre outras atividades, coordenou o Festival Música Nova de 1988 e 1989.

Entre seu afastamento político da UnB, a abertura política e o processo jurídico de reintegração, passaram-se cerca de duas décadas para o retorno de Conrado Silva à universidade federal. Retomando suas atividades acadêmicas, concluiu seu doutorado em tese com o tema: "Análise acústica de auditórios musicais depois de construídos", em 2009. Logo depois, ao completar os anos de serviço, se aposenta da universidade e volta para São Paulo, com o intuito de retomar seus trabalhos artísticos e em arquitetura acústica. Entretanto, com a saúde debilitada pela idade, vem a falecer em 2014.

O legado de Conrado Silva não se limita à sua produção artística, mas sobretudo à uma atuação que transcende as fronteiras geográficas, ideológicas e estéticas, fomentando a integração artística latino-americana, divulgando a música eletroacústica por meio das oficinas de música, dos festivais, dos cursos que idealizou e realizou. Muitos compositores devem a ele o impulso, o incentivo e a doação irrestrita. Desse fato, faço de minha experiência pessoal meu testemunho.

\section{Referências}

AHARONIÁN, Coriún. La música, la tecnología y nosotros los latinoamericanos. LULÚ, n.3, abril de 1992. Disponível em: <http://www.bazaramericano.com/musica/antologias_lulu/ musica_y\%20_tecnologia/aharorian_lamusica.htm>. Acessado em: 27.01.2009.

AHARONIÁN, Coriún. Resumen de los quince cursos latinoamericanos de música contemporánea. 2007. Disponível em: <http://www.latinoamerica-musica.net/>. Acessado em: 27.01.2009.

COELHO, João Marcos. No Calor da Hora - Música \& cultura nos anos de chumbo. São Paulo: Algol Editora, 2008. 
COELHO, João Marcos. 68 e a Música Nova. Digestivo Cultural: 25/08/2008. Disponível em: <http://www.digestivocultural.com/ensaios/imprimir.asp?codigo=268:. Acessado em: 27.01.2009.

DAVIES, Hugh (org). Repertoire International des Musiques Electroacoustiques - International Electronic Music Catalog. Electronic Music Review N. 2/3, April/July 1967. Massachusets: MIT Press, 1967.

DAL FARRA, Ricardo. El archivo de música electroacústica de compositores latinoamericanos. Fondation Daniel Langois, 2004. Disponível em: < http://www.colegiocompositores-la.org/articulos/archivos/Electroac_LatAm_Dal_Farra_e.pdf>. Acessado em: 27.01.2009.

DAL FARRA, Ricardo. The Electronic Music in Latin America. Portal Unesco, 2003. Disponível em: http://portal.unesco.org/. Acessado em: 27.01.2009.

DAL FARRA, Ricardo. Latin American Electroacoustic Music Collection. Portal Daniel Langlois Foundation for Art, Science, and Technology, 2004. Disponível em: <http://www.fondation-langlois.org/>. Acessado em: 27.01.2009.

MENDES, Gilberto. Uma Odisséia Musical. São Paulo: EdUSP, 1994.

SILVA, Conrado. Elementos de Acústica Arquitetônica. Ed. Nobel, 1982.

SILVA, Conrado. Música Eletroacústica na América Latina. ART 013 - revista da Escola de Música e Artes Cênicas abril 1985. Salvador: UFBA, 1985.

SOARES, Teresinha Rodrigues Prada. A Utopia no Horizonte da Música Nova. Tese de Doutorado - Pós-graduação em História Social. São Paulo: USP, 2006.

SOARES, Teresinha Rodrigues Prada. A Utopia no Horizonte da Música Nova. Anais do XVIII Encontro Regional da Anpuh-São Paulo (Associação Nacional de História-Seção São Paulo).

Assis, de 24 a 28 de Julho de 2006. Disponível em: <http://www.anpuhsp.org.br/downloads/>. Acessado em: 27/01/2009.

Anselmo Guerra - Possui formação em Piano pelo Conservatório Musical de Santos SP, graduação em Composição e Regência pela UNESP (1986), mestrado em Ciência da Computação pela Universidade de Brasília (1992) e doutorado em Comunicação e Semiótica pela Pontifícia Universidade Católica de São Paulo (1997). Foi pesquisador visitante no CRCA - Center for Research in computing and The Arts da Universidade da Califórnia San Diego (1995/6)Atualmente é Professor Associado da Universidade Federal de Goiás. Tem experiência na área de Artes, com ênfase em Música Computacional, atuando principalmente nos seguintes temas: composição musical, música computacional, música eletroacústica, música contemporânea. Foi coordenador do Mestrado em Música da UFG por três mandatos e é vice-presidente da Sociedade Brasileira de Música Eletroacústica - SBME. http://ufg.academia.edu/ AnselmoGuerra 